Supplementary Information

\title{
Encasing the prelithiated silicon species in the graphite scaffold: an enabling anode design for the highly-reversible, energy-dense cell model
}

Miao Bai a, Liyan Yang ${ }^{b}$, Qiurong Jia ${ }^{c}$, Xiaoyu Tang ${ }^{\text {a }}$, Yujie Liu ${ }^{\text {a }}$, Helin Wang a , Min

Zhang ${ }^{\mathrm{a}}$, Runchen Guo ${ }^{\mathrm{b}}$, Yue Ma ${ }^{\text {a* }}$

${ }^{a}$ State Key Laboratory of Solidification Processing, Center for Nano Energy Materials,

School of Materials Science and Engineering, Shaanxi Joint Laboratory of Graphene,

Northwestern Polytechnical University, Xi'an 710072, P. R. China.

${ }^{b}$ SEED Research Center, Xi'an Economic \& Technological Development Zone,

Xi'an 710014, P. R. China.

${ }^{c}$ Zhengzhou Bak Battery Co., Ltd., Zhengzhou 451450, P. R. China.

Corresponding author: mayue04@nwpu.edu.cn (Y. Ma) 

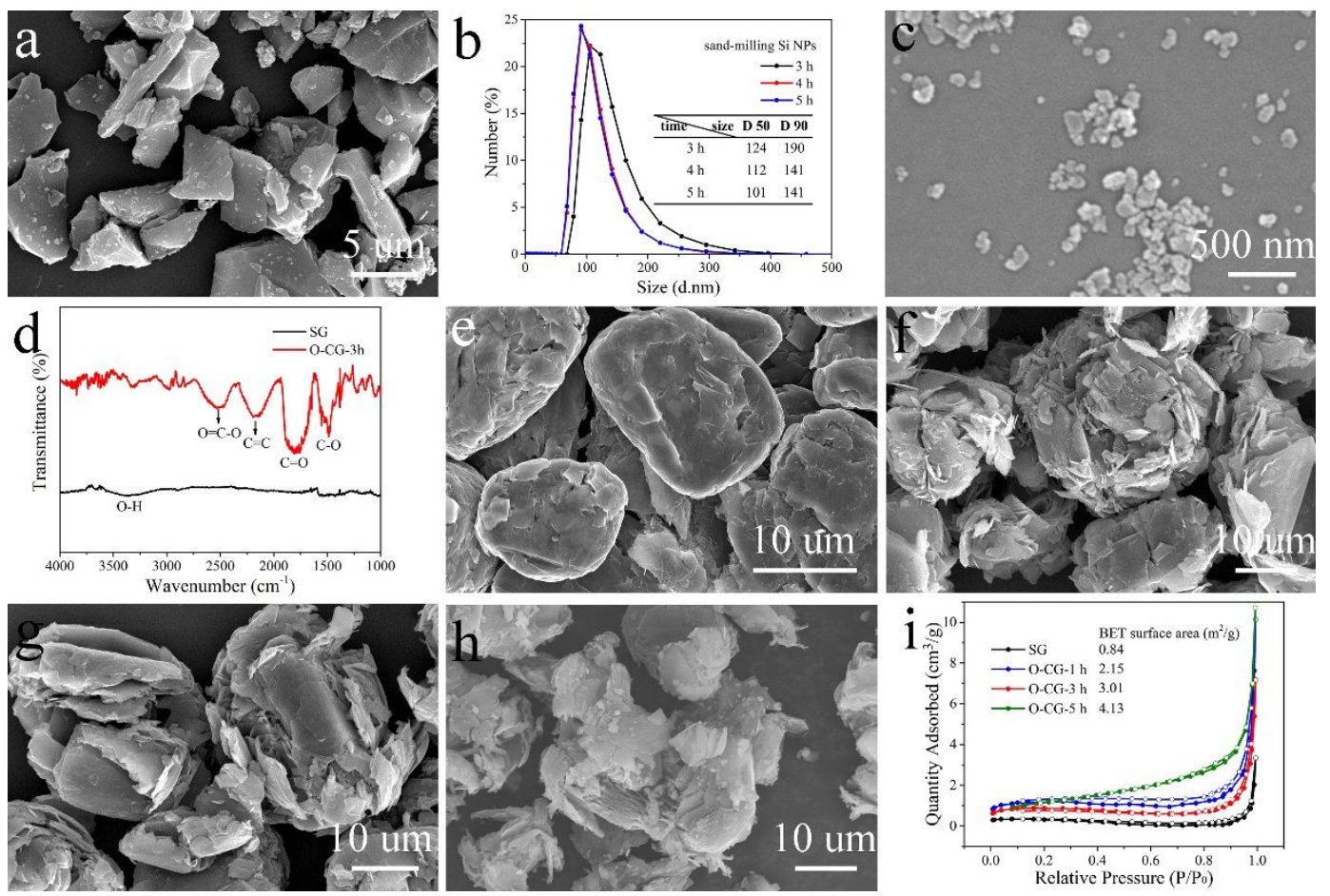

Figure S1. (a) FESEM image of Si microparticle precursor. (b) Particle size distribution (PSD) curves of the sand-milled Si NPs upon the sand-milling process for $3 \mathrm{~h}, 4 \mathrm{~h}$ and $5 \mathrm{~h}$. (c) FESEM image of Si NPs after $4 \mathrm{~h}$ sand-milling process. (d) FTIR spectra of O-CG-3 and spherical graphite particles. FESEM images of (e) spherical graphite, (f) O-CG-1, (g) O-CG-3 and (h) OCG-5. (i) $\mathrm{N}_{2}$ adsorption-desorption isotherms of spherical graphite, O-CG-1, O-CG-3 and OCG-5.

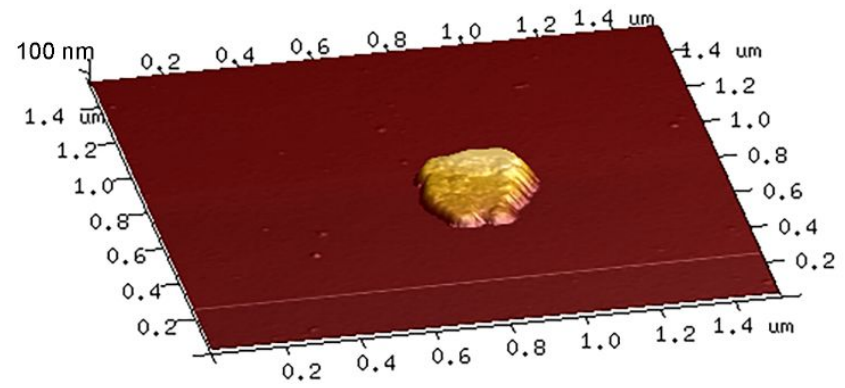

Figure S2. An atomic force microscope (AFM) image of Si NPs after $4 \mathrm{~h}$ sand-milling process in contact mode (height image) as adsorbed on a silicon surface. 

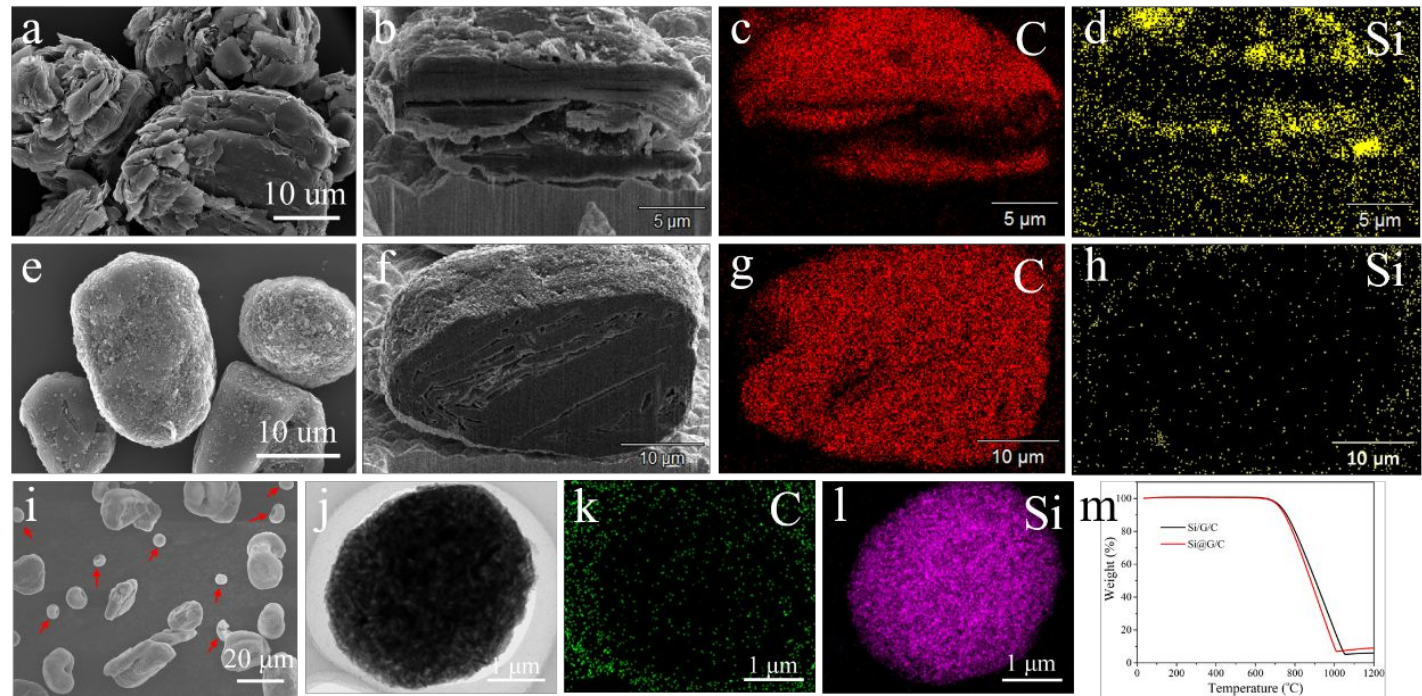

Figure S3. (a) FESEM of the Si@G/C composite. (b) The cross-sectional image of the Si@G/C composite and corresponding EDS elemental maps of (c) C and (d) Si. (e) FESEM of the Si/G/C composite. (f) The cross-sectional image of the $\mathrm{Si} / \mathrm{G} / \mathrm{C}$ composite and corresponding EDS elemental maps of (g) $\mathrm{C}$ and (h) Si. (i) FESEM image of the $\mathrm{Si} / \mathrm{G} / \mathrm{C}$ composite at low magnification. (j) TEM image of the aggregate $\mathrm{Si}$ particles in the $\mathrm{Si} / \mathrm{G} / \mathrm{C}$ composite and corresponding EDS elemental maps of (k) C and (l) Si. (m) TGA profiles of the $\mathrm{Si} / \mathrm{C} / \mathrm{C}$ and $\mathrm{Si} @ \mathrm{G} / \mathrm{C}$ composites.

EDS results of cross-sectional image provide further evidence of the uniformly encapsulation of the Si NPs in the O-CG-3 framework (Figure S3b-d). In stark contrast, the $\mathrm{Si} / \mathrm{G} / \mathrm{C}$ composite without the acid oxidization treatment exhibits the aggregated $\mathrm{Si}$ NPs concentratedly distributed on the smooth surface of graphite spheres (Figure S3e). In addition, the cross-sectional FESEM image of the Si/G/C composite (Figure S3f) and the corresponding elemental maps of $\mathrm{Si}$ and $\mathrm{C}$ further confirm the compact stacking of the graphite layers without the graphite interlayer spacing. In other words, the Si NPs only aggregated on the surface of the spherical graphite particles without the infiltration 
into the composite interior (Figure S3g and h). FESEM image of the Si/G/C composite at the low magnification shown in Figure S3i, demonstrates the Si aggregated microparticles that separated from the O-CG-3 scaffold (as marked by the red arrows in Figure S3i). TEM image of the Si aggregated microparticles in the Si/G/C composite (Figure S3j) and the corresponding EDS elemental maps (Figure S3k and 1) suggest the densely aggregation of the Si NPs without the graphite supporting layer. According to the thermogravimetric analysis (TGA) (Figure S3m), the silicon content of the $\mathrm{Si} / \mathrm{G} / \mathrm{C}$ composite $(5.6 \mathrm{wt} \%)$ is slightly smaller as compared to the $\mathrm{Si} @ \mathrm{G} / \mathrm{C}$ composite $(6.2 \mathrm{wt} \%)$
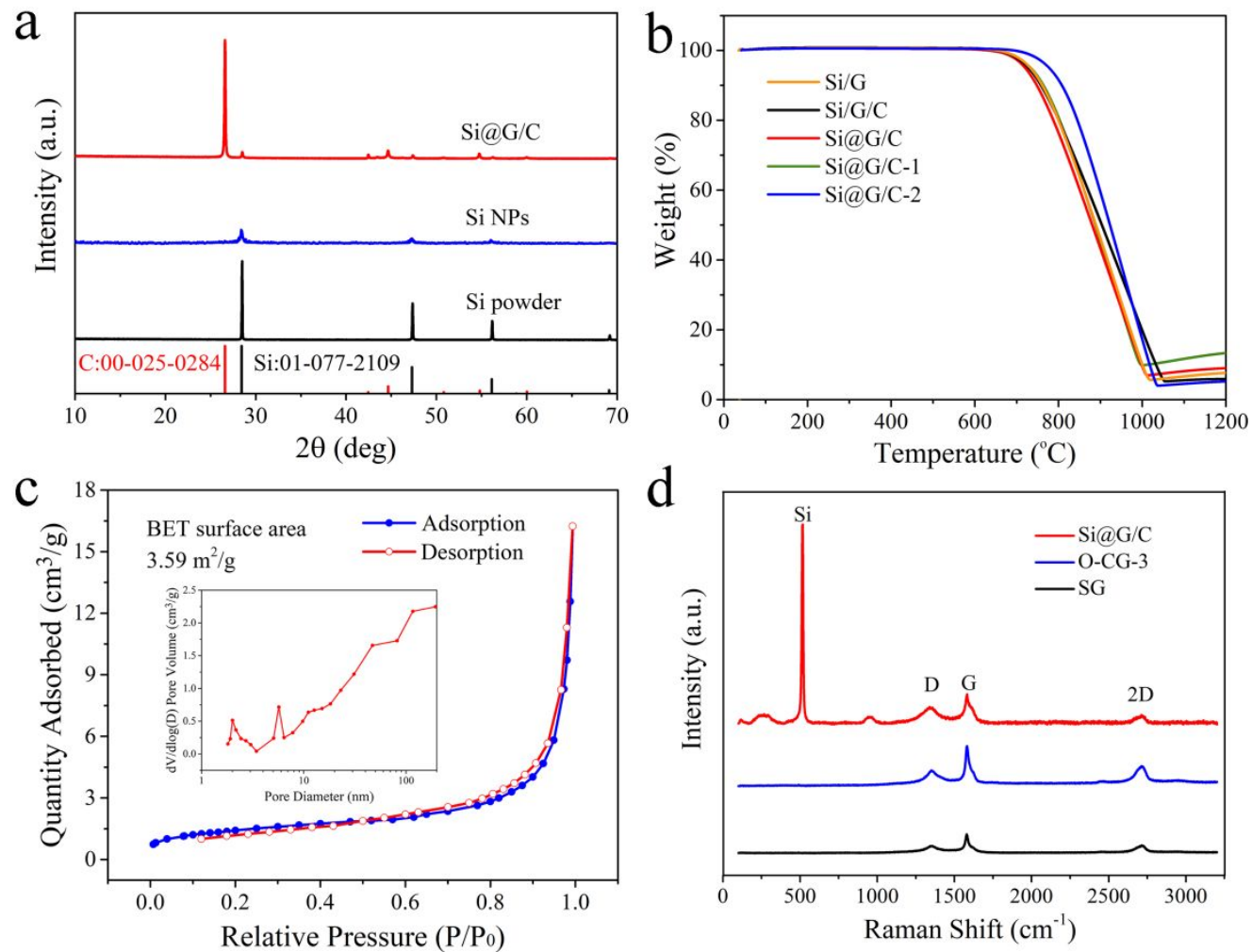

Figure S4. (a) XRD patterns of Si microparticle powder, Si NPs and the Si@G/C composite.

(b) TGA profiles of the Si/G, Si/G/C, Si@G/C, Si@G/C-1 and Si@G/C-2 composites. (c) $\mathrm{N}_{2}$ 
adsorption-desorption isotherms and corresponding pore-size distribution curve of the Si@G/C composite. (d) Raman spectra of SG, O-CG-3 and Si@G/C samples.

Figure S4a shows the XRD patterns of Si microparticle powder, Si NPs and the Si@G/C composites. For the Si@G/C composite, it can be easily concluded that the diffraction peaks can be well indexed to the (111), (220) and (311) planes of cubic Si structure (ICSD number 01-077-2109) and (002), (100), (101), (102) and (004) planes of graphite (ICSD number 00-025-0284). Compared with the Si powder, the broad peaks of milled Si NPs indicate the decreased crystalline grain size. According to Debye-Scherrer equation, the average crystallite size of Si NPs along the [111] peak is estimated as $\sim 112 \mathrm{~nm}$, which is generally consistent with the characterization result from PSD curves as shown in Figure S1b. ${ }^{1-2}$ The content of Si in the composites is measured by the TGA tests. As exhibited in Figure S4b, the weight loss originated from the carbon combustion occurs in the range of $500-1050^{\circ} \mathrm{C}$, followed by a slight weight increase due to the oxidation of Si NPs at $\sim 980^{\circ} \mathrm{C}$. Thus, the weight ratios of Si in Si/G, Si/G/C, Si@G/C, Si@G/C-1 and Si@G/C-2 composites are estimated as 6.0 wt $\%, \quad 5.6 \mathrm{wt}^{\mathrm{O}} \%, \quad 6.2 \mathrm{wt} \%, \quad 13.9 \mathrm{wt} \%$ and $3.9 \mathrm{wt}^{\mathrm{o}} \%$, respectively. ${ }^{3-4}$ The $\mathrm{N}_{2}$ adsorption/desorption isotherms were evaluated to measure the Brunauer-EmmettTeller (BET) specific surface area (SSA) of the composites. The SSA of the Si@G/C was estimated as $3.59 \mathrm{~m}^{2} \mathrm{~g}^{-1}$ (Figure S4c). ${ }^{5}$ The pore size distribution measured based the adsorption isotherm shows the existence of the mesopores ranging from 4-8 nm (inset in Figure S4c). The Raman spectra of composites were compared in Figure S4d. The Si@G/C composite exhibits the weak peak at around $290 \mathrm{~cm}^{-1}$, which is 
characteristic of the second acoustic phonon mode of Si, while the peak at around 518 $\mathrm{cm}^{-1}$ is originated from crystal structure of $\mathrm{Si}$. The G-band at $\approx 1580 \mathrm{~cm}^{-1}$ represents the $\mathrm{sp} 2$ bonded carbon atom vibration, corresponding to the first order scattering of the E2 $\mathrm{g}$ mode. The D-band at $\approx 1350 \mathrm{~cm}^{-1}$ represents the defect-induced vibrations (disordered carbon). ${ }^{6}$ Noted that the $\mathrm{I}_{\mathrm{D}} / \mathrm{I}_{\mathrm{G}}$ ratio of O-CG-3 (1.12) is higher than spherical graphite (0.94), indicating that the acid oxidization treatment has introduced the high quantity of functional groups and structural defects in the graphite scaffold. After CVD process, the $\mathrm{I}_{\mathrm{D}} / \mathrm{I}_{\mathrm{G}}$ ratio of the $\mathrm{Si} @ \mathrm{G} / \mathrm{C}$ composite further increased to 1.26 due to the additional amorphous carbon layer that formed on the composite. ${ }^{7}$
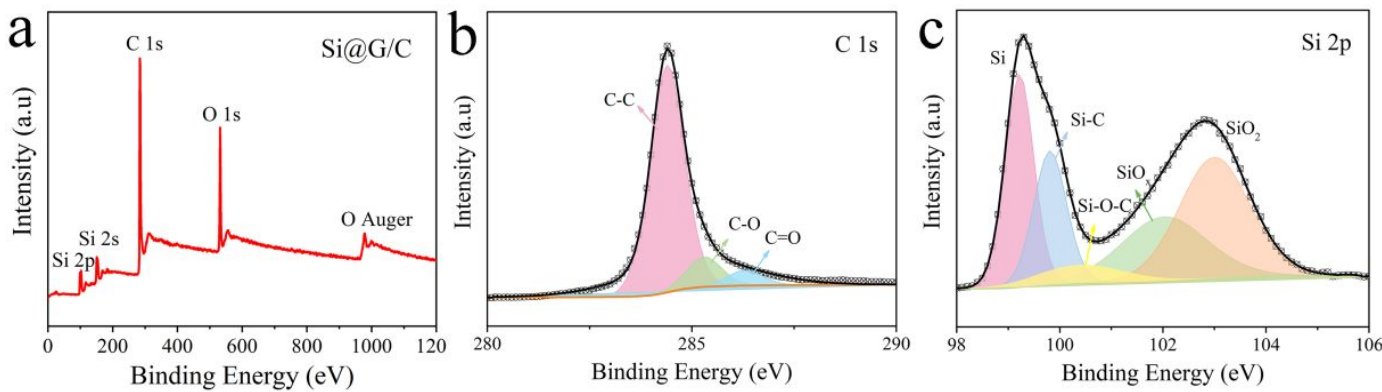

Figure S5. (a) The full XPS spectrum, (b) High-resolution C 1s core-level spectrum, and (c) High-resolution Si 2p core-level spectrum of the Si@G/C composite.

From the full survey spectrum of X-ray photoelectron spectroscopy (XPS) analysis in Figure S5a, C, Si and O elements can be detected in the Si@G/C composite. The observation of the trace amount oxygen containing groups echoes with previous FTIR characterizations of the carboxyl functional groups. Figure S5b shows the highresolution XPS spectrum of C 1s, which can be resolved into three individual peaks: C$\mathrm{C}$ at the binding energy of $284.6 \mathrm{eV}, \mathrm{C}-\mathrm{O}$ at $285.4 \mathrm{eV}$, and $\mathrm{C}=\mathrm{O}$ at $287.3 \mathrm{eV}$. Figure 
S5c shows the high-resolution XPS spectrum of Si 2p, which could be deconvoluted into four peaks. The distinct peak positioned at $98.9 \mathrm{eV}$ is ascribed to the $\mathrm{Si}-\mathrm{Si}$ bond; while the peak located at $103.6 \mathrm{eV}$ is assigned to $\mathrm{Si}-\mathrm{O}$ bond due to the partly interfacial oxidation of the Si NPs. ${ }^{8}$ In addition, the formation of Si-C bond in $100.6 \mathrm{eV}$ and SiO-C bond in $101.7 \mathrm{eV}$ confirm the rich and rational chemical bonds between $\mathrm{Si}$ and carbon, which would not only enhance the interactions between graphite and Si NPs but also increase the electrical conductivity of the electrode materials. ${ }^{9,10-11}$

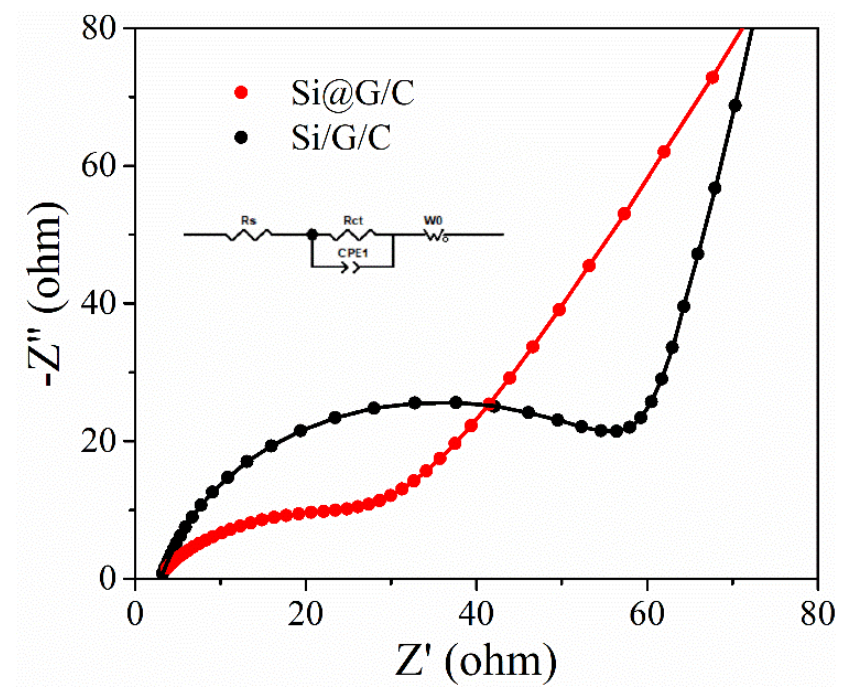

Figure S6. Nyquist plots of $\mathrm{Si} @ \mathrm{G} / \mathrm{C}$ and $\mathrm{Si} / \mathrm{G} / \mathrm{C}$ electrodes and the equivalent circuit from the EIS fitting (insert).
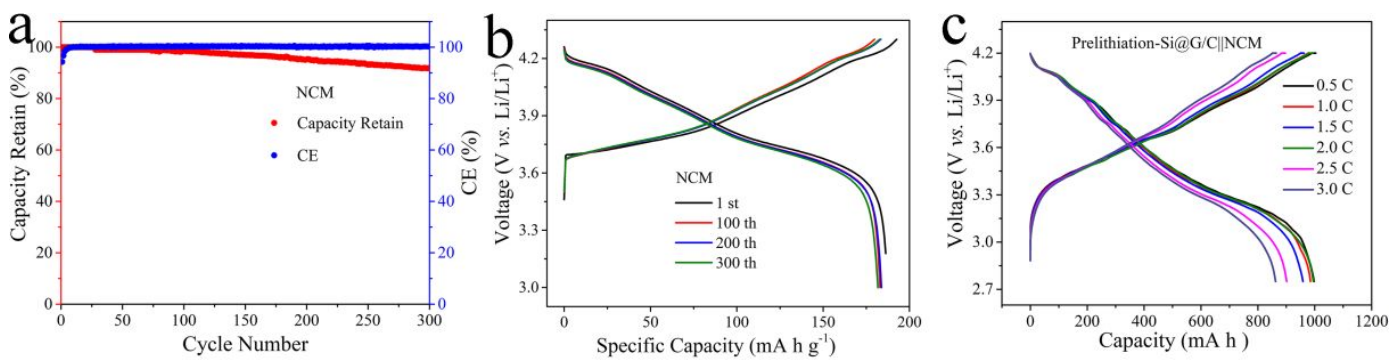
Figure S7. (a) Capacity retention of the as-fabricated NCM cathode at 0.5 C. (b) Charge and discharge profiles of as-fabricated NCM cathode for the $1^{\text {st }}, 100^{\text {th }}, 200^{\text {th }}$ and $300^{\text {th }}$ cycles. (c) Corresponding charge/discharge curves at different current densities of the prelithiatedSi@G/C ||NCM full cell.

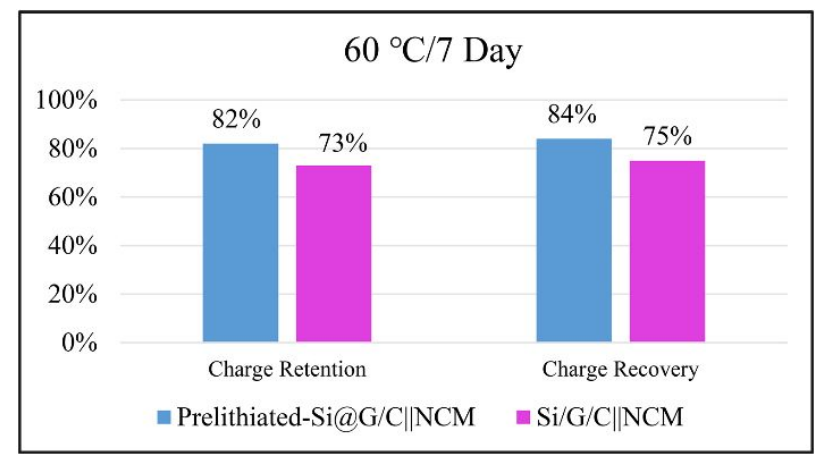

Figure S8. The charge retention and charge recovery values of the prelithiated$\mathrm{Si} @ \mathrm{G} / \mathrm{C} \| \mathrm{NCM}$ and $\mathrm{Si} / \mathrm{G} / \mathrm{C} \| \mathrm{NCM}$ after rest in $60^{\circ} \mathrm{C}$ for 7 days.

Table S1. PSD curves of sand-milling Si NPs that fabricated at the different linear velocity of the rotator.

\begin{tabular}{cccc}
\hline Time $(\mathrm{h})$ & $\begin{array}{c}\text { Linear velocity } \\
(\mathrm{m} / \mathrm{s})\end{array}$ & D 50 (nm) & D 90 (nm) \\
\hline \multirow{3}{*}{4} & 8 & 154 & 205 \\
& 9 & 143 & 178 \\
& 10 & 133 & 165 \\
& 11.5 & 112 & 141 \\
\hline
\end{tabular}

When pairing the $\mathrm{Si} @ \mathrm{G} / \mathrm{C}$ composite anode (mixing with the commercial graphite) at the areal loading mass of $161 \mathrm{~g} \mathrm{~m}^{-2}$ with the NMC cathode at loading mass of $420 \mathrm{~g}$ $\mathrm{m}^{-2}$ (double side deposition), the pilot-line produced pouch full-cell prototype (1 A h) was constructed with the capacity controlled as $1 \mathrm{~A} \mathrm{~h}$. The energy density was 
calculated based on total mass of the whole pouch cell including active material of cathode and anode, conductive additive, current collector, separator, electrolyte and aluminum-plastic pouch by below equations:

Gravimetric energy density $\left(\mathrm{W} \mathrm{h} \mathrm{kg}^{-1}\right)$

$=$ specific capacity $\left(\mathrm{mA} \mathrm{h}^{-1}\right) \times$ average voltage $(\mathrm{V})$

$=\frac{\text { capacity of the full cell }}{\text { weight of (cathode }+ \text { anode }+ \text { collector }+ \text { separtor }+ \text { electrolyte }+ \text { pouch }+ \text { SLMP })} \times$ average voltage $(V)$

(1) Gravimetric specific power density $\left(\mathrm{W} \mathrm{kg}^{-1}\right)$

$=$ gravimetric energy density $\left(\mathrm{W} \mathrm{h} \mathrm{kg}^{-1}\right) \times \mathrm{C}$ rate $\left(\mathrm{h}^{-1}\right)$

(2) Volumetric energy density $\left(\mathrm{W} \mathrm{h} \mathrm{L}^{-1}\right)$

$=$ specific capacity $\left(\mathrm{mA} \mathrm{h} \mathrm{L}^{-1}\right) \times$ average voltage $(\mathrm{V})$

$=\frac{\text { capacity of the full cell }}{\text { volumetric of the whole pouch cell }} \times$ average voltage $(\mathrm{V})$

(3).

The calculations are described as below:

When the C-rate is 0.5:

Gravimetric specific capacity $=\frac{998 \mathrm{~mA} \mathrm{~h}}{5.3+2.3+0.29+1.88+1.5+0.45+0.04 \mathrm{~g}}=84.9 \mathrm{~mA} \mathrm{~h} \mathrm{~g}^{-1}$.

Gravimetric energy density $=\left(84.9 \mathrm{~mA} \mathrm{~h} \mathrm{~g}^{-1}\right) \times(3.55 \mathrm{~V})=301.3 \mathrm{~W} \mathrm{~h} \mathrm{~kg}^{-1}$.

Gravimetric specific power density $=\left(301.3 \mathrm{Wh} \mathrm{kg}^{-1}\right) \times\left(0.5 \mathrm{~h}^{-1}\right)=150.6 \mathrm{~W} \mathrm{~kg}^{-1}$.

Volumetric energy density $=\frac{998 \mathrm{mAh}}{5 \times 5 \times 3 \times 10^{-4} \mathrm{~L}} \times(3.55 \mathrm{~V})=472.4 \mathrm{~W} \mathrm{~h} \mathrm{~L}^{-1}$.

We also calculate the specific capacity, energy density and power density of the prelithiated-Si@G/C | $\mathrm{NCM}$ pouch cell at different C-rates based on the total mass of the whole pouch cell or merely based on the active material, as shown in Table S2. 
Table S2. The calculation results of the specific capacity, energy density and power density of the prelithiated-Si@G/C $\|$ NCM pouch cell at different C-rates (based on the total mass of the whole pouch cell or merely based on the active materials, respectively).

\begin{tabular}{c|ccc|ccc}
\hline & \multicolumn{2}{|c|}{ Based on whole pouch cell } & \multicolumn{3}{c}{ Based on active material } \\
\hline C-rate & $\begin{array}{c}\text { Specific } \\
\text { capacity } \\
\left(\mathrm{mA} \mathrm{h} \mathrm{g}^{-1}\right)\end{array}$ & $\begin{array}{c}\text { Energy } \\
\text { density } \\
\left(\mathrm{W} \mathrm{h} \mathrm{kg}^{-1}\right)\end{array}$ & $\begin{array}{l}\text { Power } \\
\text { density } \\
\left(\mathrm{W} \mathrm{kg}^{-1}\right)\end{array}$ & $\begin{array}{c}\text { Specific } \\
\text { capacity } \\
\left(\mathrm{mA} \mathrm{h} \mathrm{g}^{-1}\right)\end{array}$ & $\begin{array}{c}\text { Energy } \\
\text { density } \\
\left(\mathrm{W} \mathrm{h} \mathrm{kg}^{-1}\right)\end{array}$ & $\begin{array}{c}\text { Power } \\
\text { density } \\
\left(\mathrm{W} \mathrm{kg}^{-1}\right)\end{array}$ \\
\hline 0.5 & 84.9 & 301.3 & 150.6 & 1313 & 466.1 & 233.1 \\
1 & 84.5 & 299.9 & 299.9 & 126.3 & 448.4 & 448.4 \\
1.5 & 81.8 & 290.4 & 435.6 & 122.3 & 434.3 & 651.5 \\
2 & 79.2 & 281.2 & 562.3 & 118.4 & 420.3 & 840.6 \\
2.5 & 76.6 & 271.9 & 679.8 & 114.4 & 406.2 & 1015.7 \\
3 & 73.1 & 259.5 & 778.6 & 109.2 & 387.8 & 1163.5 \\
\hline
\end{tabular}

Table 3. A broad performance comparison of prelithiated-Si@G/C ||NCM devices versus stateof-the-art full devices from literature employing Si anodes.

\begin{tabular}{|c|c|c|c|c|}
\hline $\begin{array}{c}\text { Material type } \\
\text { (Si content } \\
\text { wt } \%)\end{array}$ & Synthesis strategy & Cathode & $\begin{array}{c}\text { Max. specific } \\
\text { energy } \\
\text { density } \\
\mathrm{W} \mathrm{h} \mathrm{kg}^{-1} \\
\end{array}$ & $\begin{array}{c}\text { Cyclability } \\
\text { (on } \\
\text { discharge) }\end{array}$ \\
\hline $\begin{array}{c}\mathrm{Si} @ \mathrm{G} / \mathrm{C} \\
(6.2 \%) \\
\text { (this work) }\end{array}$ & $\begin{array}{c}\text { Oxidation } \\
\text { process, } \\
\text { in situ assembly, } \\
\text { CVD }\end{array}$ & $\mathrm{NCM}$ & $473.7 @ 0.5 \mathrm{C}$ & $\begin{array}{c}84 \% @ 500 \\
\text { cycles }(0.5 \mathrm{C})\end{array}$ \\
\hline $\begin{array}{l}\text { Epoxy-Si-G } \\
(47.8 \%)^{12}\end{array}$ & $\begin{array}{c}\text { In situ } \\
\text { hybridization, } \\
\text { epoxy tether }\end{array}$ & $\mathrm{LiCoO}_{2}$ & $437 @ 0.4 \mathrm{C}$ & $\begin{array}{c}84.1 \% @ 150 \\
\text { cycles (1C) }\end{array}$ \\
\hline $\begin{array}{l}\text { Carbon-coated } \\
\text { Si nanosheets }{ }^{13}\end{array}$ & $\begin{array}{l}\text { Magnesiothermic } \\
\text { reduction, HF } \\
\text { etching, } \\
\text { hydrothermal, } \\
\text { carbonization }\end{array}$ & $\mathrm{LiCoO}_{2}$ & $416 @ 0.5 \mathrm{C}$ & $\begin{array}{c}80 \% @ 50 \\
\text { cycles }(0.5 \mathrm{C})\end{array}$ \\
\hline $\begin{array}{c}\text { Carbon spheres } \\
@ \mathrm{Si} @ \mathrm{C} \\
(42 \%)^{14}\end{array}$ & $\begin{array}{l}\text { In situ assembly, } \\
\text { reduction process }\end{array}$ & $\mathrm{LiFePO}_{4}$ & $317.8 @ 0.5 \mathrm{C}$ & $\begin{array}{c}80 \% @ 50 \\
\text { cycles }(0.5 \mathrm{C})\end{array}$ \\
\hline $\begin{array}{l}\text { Graphene-caged } \\
\qquad \mathrm{Si}^{15}\end{array}$ & $\begin{array}{l}\text { Magnesiothermic } \\
\text { reduction, CVD }\end{array}$ & $\mathrm{LiCoO}_{2}$ & $329 @ 1 \mathrm{C}$ & $\begin{array}{l}87 \% @ 30 \\
\text { cycles (1C) }\end{array}$ \\
\hline Carbon-coated & Magnesiothermic & $\mathrm{LiCoO}_{2}$ & $409 @ 0.2 \mathrm{C}$ & $84 \% @ 50$ \\
\hline
\end{tabular}




\section{References}

(1) Zhu, B.; Jin, Y.; Tan, Y.; Zong, L.; Hu, Y.; Chen, L.; Chen, Y.; Zhang, Q.; Zhu, J. Scalable Production of Si Nanoparticles Directly from Low Grade Sources for Lithium-Ion Battery Anode. Nano Lett. 2015, 15, DOI: 10.1021/acs.nanolett.5b01698.

(2) Gao, X.; Li, J.; Xie, Y.; Guan, D.; Yuan, C. A Multilayered Silicon-Reduced Graphene Oxide Electrode for High Performance Lithium-Ion Batteries. Acs Appl. Mater. Interfaces 2015, 7 (15), 7855-7862, DOI: 10.1021/acsami.5b01230.

(3) Xu, T.; Wang, D.; Qiu, P.; Zhang, J.; Wang, Q.; Xia, B.; Xie, X. In situ synthesis of porous Si dispersed in carbon nanotube intertwined expanded graphite for high-energy lithium-ion batteries. Nanoscale 2018, 10 (35), 16638-16644, DOI: 10.1039/C8NR04587A.

(4) Xu, Q.; Li, J.-Y.; Sun, J.-K.; Yin, Y.-X.; Wan, L.-J.; Guo, Y.-G. Watermelon-Inspired Si/C Microspheres with Hierarchical Buffer Structures for Densely Compacted Lithium-Ion Battery Anodes. Adv. Energy Mater. 2017, 7 (3), 1601481, DOI: 10.1002/aenm.201601481.

(5) Choi, M.; Kim, J.-C.; Kim, D.-W. Waste Windshield-Derived Silicon/Carbon Nanocomposites as High-Performance Lithium-Ion Battery Anodes. Sci. Rep. 2018, 8, DOI: 10.1038/s41598-018-19529-1.

(6) Lin, Y.; Chen, Y.; Zhang, Y.; Jiang, J.; He, Y.; Lei, Y.; Du, N.; Yang, D. Wet-chemical synthesized MCMB@Si@C microspheres for high-performance lithium-ion battery anodes. Chem. Commun. 2018, 54 (68), 9466-9469, DOI: 10.1039/C8CC04797A.

(7) Chang, J.; Huang, X.; Zhou, R.; Cui, S.; Hallac, P.; Jiang, J.; T Hurley, P.; Chen, J. Lithium-Ion Batteries: Multilayered Si Nanoparticle/Reduced Graphene Oxide Hybrid as a High-Performance Lithium-Ion Battery Anode. Adv. Mater. 2014, 26, 665, DOI: 10.1002/adma.201470028.

(8) Philippe, B.; Dedryvère, R.; Gorgoi, M.; Rensmo, H.; Gonbeau, D.; Edström, K. Improved Performances of Nanosilicon Electrodes Using the Salt LiFSI: A Photoelectron Spectroscopy Study. J. Am. Chem. Soc. 2013, 135 (26), 9829-9842, DOI: 10.1021/ja403082s.

(9) Zhou, J.; Lan, Y.; Zhang, K.; Xia, G.; Du, J.; Zhu, Y.; Qian, Y. In situ growth of carbon nanotube wrapped $\mathrm{Si}$ composites as anodes for high performance lithium ion batteries. Nanoscale 2016, 8 (9), 4903-4907, DOI: 10.1039/C5NR08961A.

(10) Zhou, J.; Jiang, Z.; Cai, W.; Liu, X.; Zhu, Y.; Lan, Y.; Ma, K.; Qian, Y. Solvothermal synthesis of a silicon hierarchical structure composed of $20 \mathrm{~nm}$ Si nanoparticles coated with carbon for high performance Li-ion battery anodes. Dalton. Trans. 2016, 45 (35), 13667-13670, DOI: $10.1039 /$ C6DT02551J.

(11) Shao, R.; Niu, J.; Zhu, F.; Dou, M.; Zhang, Z.; Wang, F. A facile and versatile strategy towards high-performance $\mathrm{Si}$ anodes for Li-ion capacitors: Concomitant conductive network 
construction and dual-interfacial engineering. Nano Energy 2019, 63, 103824, DOI: https://doi.org/10.1016/j.nanoen.2019.06.020.

(12) Liu, W.; Li, H.; Jin, J.; Wang, Y.; Zhang, Z.; Chen, Z.; Wang, Q.; Chen, Y.; Paek, E.; Mitlin, D. Synergy of Epoxy Chemical Tethers and Defect-Free Graphene in Enabling Stable Lithium Cycling of Silicon Nanoparticles. Angew. Chem., Int. Ed. 2019, 58 (46), 16590-16600, DOI: 10.1002/anie.201906612.

(13) Chen, S.; Chen, Z.; Xu, X.; Cao, C.; Xia, M.; Luo, Y. Scalable 2D Mesoporous Silicon Nanosheets for High-Performance Lithium-Ion Battery Anode. Small 2018, 14 (12), 1703361, DOI: $10.1002 / \mathrm{smll} .201703361$.

(14) Jiang, H.; Wang, S.; Shao, Y.; Wu, Y.; Shen, J.; Hao, X. Hollow Triple-Layer Puff-like HCs@Si@C Composites with High Structural Stability for High-Performance Lithium-Ion Battery. ACS Appl. Mater. Interfaces 2019, 2 (1), 896-904, DOI: 10.1021/acsaem.8b01991.

(15) Nie, P.; Le, Z.; Chen, G.; Liu, D.; Liu, X.; Wu, H. B.; Xu, P.; Li, X.; Liu, F.; Chang, L.; Zhang, X.; Lu, Y. Graphene Caging Silicon Particles for High-Performance Lithium-Ion Batteries. Small 2018, 14 (25), 1800635, DOI: 10.1002/smll.201800635.

(16) Shi, M.; Nie, P.; Fu, R.; Fang, S.; Li, Z.; Dou, H.; Zhang, X. Catalytic Growth of Graphitic Carbon-Coated Silicon as High-Performance Anodes for Lithium Storage. Energy Technol. 2019, 7 (10), 1900502, DOI: 10.1002/ente.201900502. 